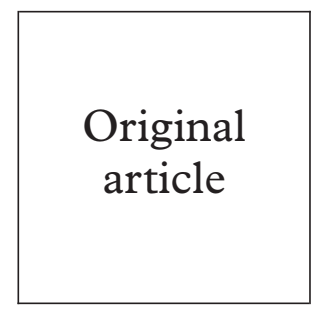

Original article

International Centre

for Reproductive

Health, University of

Ghent, Belgium

K Fonck

P Claeys

M Temmerman

Kenya Medical

Women's Association,

Nairobi, Kenya

N Kidula

Department of

Medical Microbiology,

University of Nairobi,

Kenya

W Jaoko

B Estambale

J Ndinya-Achola

J Bwayo

Public Health

Department, Nairobi

City Council, Kenya

P Kirui

Correspondence to: Professor Marleen

Temmerman, ICRH,

Department of Obstetrics

and Gynecology, University

of Ghent, De Pintelaan 185,

9000 Ghent, Belgium

Accepted for publication

2 November 1999

\title{
Validity of the vaginal discharge algorithm among pregnant and non-pregnant women in Nairobi, Kenya
}

\author{
K Fonck, N Kidula, W Jaoko, B Estambale, P Claeys, J Ndinya-Achola, P Kirui, J Bwayo, \\ M Temmerman
}

Objective: To evaluate the validity of different algorithms for the diagnosis of gonococcal and chlamydial infections among pregnant and non-pregnant women consulting health services for vaginal discharge in Nairobi, Kenya.

Methods: Cross sectional study among 621 women with complaints of vaginal discharge in three city council clinics between April and August 1997. Women were interviewed and examined for symptoms and signs of sexually transmitted infections (STIs). Specimens were obtained for laboratory diagnosis of genital infections, HIV, and syphilis. The data were used to evaluate the Kenyan flow chart as well as several other generated algorithms.

Results: The mean age was 24 years and 334 (54\%) were pregnant. The overall prevalence rates were: $50 \%$ candidiasis, $23 \%$ trichomoniasis, $9 \%$ bacterial vaginosis, $7 \%$ gonorrhoea, $9 \%$ chlamydia, $7 \%$ syphilis, and $22 \%$ HIV. In non-pregnant women, gonococcal and chlamydial infection was significantly associated with (1) demographic and behavioural risk markers such as being single, younger than 20 years, multiple sex partners in the previous 3 months; (2) symptom fever; and (3) signs including presence of yellow or bloody vaginal discharge, cervical mucopus, cervical erythema, and friability. Among pregnant women only young age, dysuria, and fever were significantly associated with cervical infection. However, none of these variables was either sensitive or specific enough for the diagnosis of cervical infection. Several algorithms were generated and applied to the study data. The algorithm including risk markers performed slightly better than the current Kenyan algorithm.

Conclusion: STIs form a major problem in the Nairobi area and should be addressed accordingly. None of the tested algorithms for the treatment of vaginal discharge would constitute a marked improvement of the existing flow chart. Hence, better detection tools for the specific aetiology of vaginal discharge are urgently needed.

(Sex Transm Inf 2000;76:33-38)

Keywords: algorithm; sexually transmitted diseases; pregnancy; Kenya

\section{Introduction}

Neisseria gonorrhoeae (NG) and Chlamydia trachomatis (CT) are two common causes of genital tract infections that have a major impact on health, particularly of women and neonates in developing countries. These infections are also known to facilitate the sexual transmission of human immunodeficiency virus (HIV). ${ }^{1-3}$ Therefore, sexually transmitted disease (STD) control activities not only prevent complications but also offer an additional strategy for the prevention of HIV. ${ }^{4-6}$

As laboratory detection methods for genital infections are expensive and not widely available in developing countries, diagnostic algorithms based on clinical signs and symptoms have been proposed by the World Health Organisation (WHO) as a tool for better management of patients presenting with genital tract problems at the primary healthcare level. The algorithms for genital ulcer disease as well as for urethral discharge have been successfully adapted for use in different countries. The flow chart for vaginal discharge, however, poses problems owing to the number and diversity of the pathogens. To address this problem, a simple risk score for the identification of NG and/or CT infections in women with complaints of vaginal discharge has been developed $^{7}$ : hence, this would result in a reduction of overtreatment costs as well as the occurrence of side effects.

In Kenya, the algorithms for STD treatment have been derived from the WHO guidelines and locally adapted by an expert committee. The current vaginal discharge algorithm has been in use for several years. At the initial visit, a woman with vaginal discharge without abdominal pain receives treatment for vaginal pathogens while treatment for pelvic inflammatory disease (PID) is reserved for accompanying abdominal pain and tenderness (fig 1). Upon follow up after 7 days, women previously treated for vaginal conditions are treated for cervical infections if there is no improvement. No risk scores or genital examination are included in the flow chart.

Following this flow chart, women with cervical infections are systematically missed at the first visit unless abdominal pain is present. In addition, many of the women with NG/CT infection might be lost to follow up especially if their symptoms have improved as a result of the vaginal infection treatment received. On the other hand, many pregnant women with 


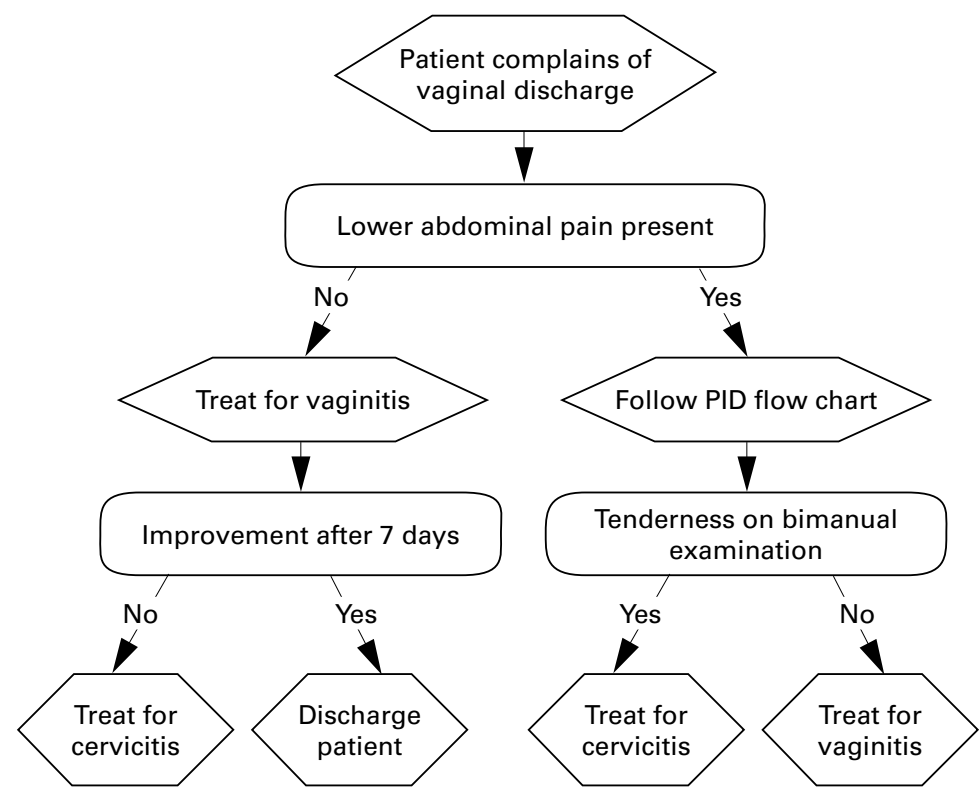

Figure 1 Algorithm for vaginal discharge used as the national policy in Kenya.

discharge and abdominal pain - two conditions often occurring in pregnancy-might unnecessarily be treated for cervical infections at the first visit. From personal communications with healthcare workers it became obvious that they often rely on their personal (clinical) judgment to treat women for cervical infection at the first visit. To this effect they seem to take into consideration risks, signs, and symptoms to make a diagnosis. Hence, very often this algorithm defeats its public health goal, the control of cervical infections, and risks of undermining the credibility of the services.

We thus undertook this study to validate the use of the current Kenyan clinical algorithm for vaginal discharge, which is one of the most frequent reasons for consulting the health service. We validated addition of risk scores as well as inclusion of signs and symptoms among pregnant and non-pregnant women.

\section{Patients and methods}

DATA COLLECTION

The study was conducted between April and August 1997 at two peripheral health centres (PHC) and at the major STD referral clinic (STC) run by the Nairobi City Council (NCC). The contact with the patient took place in Kiswahili. All women with spontaneous or prompted complaints of vaginal discharge with or without other symptoms, attending any of these clinics, were enrolled into the study after obtaining informed consent. After being routinely examined by the clinical officer according to the national guidelines using the syndromic approach, the women were seen by the research doctor. Subjects were interviewed about their marital, educational, and occupational status using a standardised structured questionnaire. Sexual, obstetric, and gynaecological histories were taken and details of the current genital tract complaint were noted. Each patient received a full gynaecological investigation including speculum examination and bimanual palpa- tion. Endocervical swabs were taken for $N$ gonorrhoeae isolation and $C$ trachomatis polymerase chain reaction (PCR) and vaginal swabs for wet preparation, $\mathrm{pH}$ testing, and potassium hydroxide testing (sniff test). The colour of the discharge was noted. After pretest counselling a $10 \mathrm{ml}$ sample of venous blood was drawn for syphilis serology and HIV-1 testing.

\section{LABORATORY PROCEDURES}

Wet mounts were analysed directly at STC and from the PHC clinics they were transported in a drop of saline to the laboratory of the department of medical microbiology, University of Nairobi. The wet mounts were examined for the presence of motile Trichomonas vaginalis and of yeast cells indicative of Candida albicans. In the laboratory, vaginal smears were heat fixed, Gram stained, and examined for the presence of clue cells, indicative of bacterial vaginosis, and for yeast. The diagnosis of $C$ albicans was made by wet prep and Gram stain. Bacterial vaginosis was defined by the presence of at least three of the following criteria ${ }^{8}{ }^{9}:$ (1) vaginal fluid $\mathrm{pH}>4.5$; (2) release of a fishy amine odour from vaginal fluid mixed with $10 \%$ potassium hydroxide; (3) presence of clue cells; and (4) vaginal discharge. Cervical swabs for $N$ gonorrhoeae isolation were inoculated directly onto Thayer-Martin medium and incubated in a candle extinction jar at $33-35^{\circ} \mathrm{C}$ for 24-48 hours. Cervical swabs for $C$ trachomatis PCR were processed in the laboratory (Abbott). Venous blood samples were tested for syphilis using the rapid plasma reagin test (RPR test, Becton Dickenson) and for HIV-1 using ELISA Detect (Biotech) and Recombigent (Cambridge).

DATA ANALYSIS AND DEFINITIONS

Data were entered and analysed in SPSS for windows (SPSS, Chicago, IL, USA). In univariate analysis, the odds ratio (OR) and 95\% confidence intervals (CI) were used for the measurement of associations. Comparisons were made using Pearson's $\chi^{2}$ and Fisher's exact tests. Means were compared using the Student's $t$ test. Stepwise logistic regression was used to take into account risk factors, symptoms, and signs related to the presence of gonococcal and chlamydial infection.

The principal outcome was the presence of cervical infections. Cervical infections were defined as the presence of either gonococcal or chlamydial infections or both. Different algorithms were applied to the study population based on personal data from the interview and physical examination. We used the results of the analysis of association between risk, symptoms, and signs to create six different algorithms. Algorithm A was the flow chart as in use in Kenya (fig 1). Algorithm B is the Kenyan algorithm but without the abdominal examination. Algorithm $\mathrm{C}$ includes a risk assessment of the patient. This is based on the WHO algorithm with risk score, but without presence of symptoms in the partner. Also, the risk assessment we used was simplified and considers the risk score positive if any of the risk factors are present whereas the WHO algorithm 
Table 1 Demographic characteristics of 287 non-pregnant and 334 pregnant women with vaginal discharge in Nairobi, Kenya

\begin{tabular}{|c|c|c|c|c|c|c|}
\hline \multirow[b]{2}{*}{ Mean age } & \multicolumn{2}{|c|}{$\begin{array}{l}\text { Non-pregnant } \\
(n=287) \text { n or } \\
\text { mean (\% or } \\
\text { range) }\end{array}$} & \multicolumn{2}{|c|}{$\begin{array}{l}\text { Pregnant } \\
(n=334) \text { n or } \\
\text { mean (\% or } \\
\text { range) }\end{array}$} & \multirow[t]{2}{*}{ OR $(95 \% C I)$} & \multirow{2}{*}{$\frac{p \text { Value }}{<0.001}$} \\
\hline & 25 & $(15-52)$ & 23 & $(16-41)$ & & \\
\hline Younger than 20 years & 55 & (19) & 72 & $(22)$ & $0.9(0.7-1.2)$ & 0.3 \\
\hline Single & 114 & $(40)$ & 69 & (21) & $1.9(1.5-2.5)$ & $<0.001$ \\
\hline Housewife/unemployed & 146 & (51) & 220 & (66) & $0.5(0.4-0.8)$ & $<0.001$ \\
\hline Schooling up to primary & 163 & $(57)$ & 193 & $(58)$ & $1.0(0.7-1.3)$ & 0.06 \\
\hline$>1$ partner past 3 months & 32 & (11) & 11 & (3) & $3.4(1.7-6.6)$ & $<0.001$ \\
\hline New partner past 3 months & 38 & (13) & 14 & (4) & $3.2(1.7-5.7)$ & $<0.001$ \\
\hline Mean age at sexual debut & 18 & $(10-30)$ & 18 & $(12-30)$ & & 0.7 \\
\hline Ever used condoms & 128 & (45) & 112 & (34) & $1.3(1.1-1.6)$ & 0.002 \\
\hline Mean number pregnancies & 2.0 & $(0-11)$ & & $(0-6)$ & & 0.002 \\
\hline
\end{tabular}

requires at least two risk factors. Algorithm $\mathrm{D}$ is based on the presence of yellow or bloody vaginal discharge. Algorithm E included presence of endocervical mucopus. And algorithm F combined the risk score and the presence of yellow or bloody vaginal discharge. The microbiological results were used as gold standard for cervical infections. The validity of the algorithms was evaluated by calculating their sensitivity, specificity, and positive predictive value compared with the gold standard.

We determined the correct treatment rate and the cost for each algorithm. Details on definitions and calculations are not presented here but can be obtained from the authors.

\section{Results}

SOCIODEMOGRAPHIC FACTORS AND PREVALENCE OF STDS

A total of 621 women with complaints of vaginal discharge were enrolled in the study. In STC, located in downtown Nairobi, 214 women were recruited and 255 and 152 were recruited in the two health centres, both located in the suburbs of Nairobi. The women attending the STD clinic were more often single, employed, and had more sex partners. Three hundred and thirty four $(54 \%)$ of the women were pregnant at the time of the interview. The demographic and social characteristics of pregnant women compared with nonpregnant women are shown in table 1 . Significantly, there were more single nonpregnant women and they had had more sex partners in the past 3 months. Pregnant women on the other hand were younger.

The overall prevalence of reproductive tract infections (RTI) is shown in table 2. The prevalence of $N$ gonorrhoeae and $C$ trachomatis was $7 \%$ and $9 \%$ respectively and the overall cervical infection prevalence was $16 \%$. The majority of women had vaginal infections caused by $C$ albicans (51\%), T vaginalis (23\%), and bacterial vaginosis (9\%). The prevalence of HIV was $22 \%$ and $7 \%$ of the women were RPR positive. One of the peripheral health centres had the highest prevalence for almost all conditions whereas in the STD referral clinic $C$ albicans was most prevalent. The prevalence of the RTI for pregnant and non-pregnant women was compared (table 2). Non-pregnant women had significantly more $N$ gonorrhoeae, genital ulcers, and HIV-1 infection. Pregnant women had more candidiasis.

VARIABLES RELATED TO GONOCOCCAL AND CHLAMYDIAL INFECTIONS

The univariate relation between NG/CT infection and risk factors, symptoms, and clinical signs for pregnant and non-pregnant women is shown in table 3. Several risk markers were associated with NG/CT infection in nonpregnant women, whereas being younger than 20 years old is only associated with NG/CT infection in pregnant women. Having more than one sex partner is a rare event among pregnant women.

Of the symptoms, only fever is consistently associated with NG/CT infection for both groups of women although its prevalence is low. Some symptoms on the other hand are more indicative of not having NG/CT infection.

Signs associated with NG/CT infection among non-pregnant women were yellow or bloody vaginal discharge, presence of purulent or bloody endocervical mucopus, cervical erythema, and cervical friability. None of these signs was associated with NG/CT infection in the group of pregnant women. None of the variables, however, was both sensitive $(>60 \%)$ and specific ( $>60 \%)$ enough for the presence of cervical infection. Multivariate analysis including all variables significantly associated with NG/CT infection $(p \leqslant 0.05)$, was performed for both groups of women. Among nonpregnant women, only reporting multiple sex partners in the past 3 months and yellow or bloody vaginal discharge remained significantly associated. Among pregnant women, only age and dysuria remained significantly associated.

Table 2 Prevalence of RTI and HIV among 287 non-pregnant and 334 pregnant women with vaginal discharge

\begin{tabular}{|c|c|c|c|c|c|}
\hline & $\begin{array}{l}\text { Total }(n=621) \\
\text { No }(\%)\end{array}$ & $\begin{array}{l}\text { Non-pregnant } \\
\text { women }(n=287) \\
\text { No }(\%)\end{array}$ & $\begin{array}{l}\text { Pregnant women } \\
(n=334) \\
\text { No }(\%)\end{array}$ & $\begin{array}{l}\text { Odds ratio } \\
(95 \% \mathrm{CI})\end{array}$ & $p$ Value \\
\hline \multicolumn{6}{|l|}{ Cervical or vaginal pathogens } \\
\hline N gonorrhoeae (NG) & $44(7)$ & $34(12)$ & $10(3)$ & $4.0(2.0-7.9)$ & $<0.001$ \\
\hline$C$ trachomatis (CT) & $58(9)$ & $22(8)$ & $36(11)$ & $0.7(0.4-1.2)$ & 0.1 \\
\hline $\mathrm{NG}$ and/or CT & $97(16)$ & $53(19)$ & $44(13)$ & $1.4(1.0-2.0)$ & 0.05 \\
\hline$C$ albicans & $314(51)$ & $132(46)$ & $182(55)$ & $0.8(0.7-1.0)$ & 0.02 \\
\hline$T$ vaginalis & $145(23)$ & $59(21)$ & $86(26)$ & $0.8(0.6-1.1)$ & 0.08 \\
\hline Bacterial vaginosis & $53(9)$ & $28(10)$ & $25(8)$ & $1.2(0.7-13.8)$ & 0.3 \\
\hline Genital ulcer & $34(6)$ & $22(8)$ & $12(4)$ & $2.1(1.1-4.2)$ & 0.02 \\
\hline $\begin{array}{l}\text { No cervical or vaginal } \\
\text { pathogens or flora changes }\end{array}$ & $172(28)$ & $82(30)$ & $90(27)$ & $1.1(0.8-1.4)$ & 0.3 \\
\hline \multicolumn{6}{|l|}{ Serology } \\
\hline RPR+ & $42(7)$ & $20(7)$ & $22(7)$ & $1.1(0.6-1.9)$ & 0.5 \\
\hline HIV-1+ & $137(22)$ & $72(25)$ & $65(20)$ & $1.2(1.0-1.7)$ & 0.05 \\
\hline
\end{tabular}


Table 3 Association between risk factors, symptoms and signs, and gonococcal (NG) or chlamydial (CT) infection among 287 non-pregnant women and 334 pregnant women, consulting for vaginal discharge *

\begin{tabular}{|c|c|c|c|c|c|c|c|c|}
\hline & \multicolumn{4}{|c|}{ Non-pregnant women $(n=287)$} & \multicolumn{4}{|c|}{ Pregnant women $(n=334)$} \\
\hline & $\begin{array}{l}N G / C T+v e \\
(n=53) \\
\text { No }(\%)\end{array}$ & $\begin{array}{l}N G / C T-v e \\
(n=234) \\
\text { No }(\%)\end{array}$ & $\begin{array}{l}\text { Odds ratio } \\
(95 \% \text { CI) }\end{array}$ & $p$ Value & $\begin{array}{l}N G / C T+v e \\
(n=44) \\
\text { No }(\%)\end{array}$ & $\begin{array}{l}N G / C T-v e \\
(n=290) \\
\text { No }(\%)\end{array}$ & $\begin{array}{l}\text { Odds ratio } \\
(95 \% \text { CI) }\end{array}$ & $p$ Value \\
\hline \multicolumn{9}{|l|}{ Risk determinants } \\
\hline Single & $27(51)$ & $87(37)$ & $1.7(1.0-3.2)$ & 0.05 & $10(23)$ & $59(20)$ & $1.2(0.5-2.5)$ & 0.4 \\
\hline Age $<20$ & $15(28)$ & $40(17)$ & $1.9(1.0-3.8)$ & 0.05 & $20(46)$ & $52(18)$ & $3.8(2.0-7.5)$ & $<0.001$ \\
\hline Condom use & $22(42)$ & $106(46)$ & $0.8(0.5-1.5)$ & 0.3 & $12(27)$ & $100(35)$ & $0.7(0.4-1.4)$ & 0.2 \\
\hline$>1$ sex partner & $14(26)$ & $18(8)$ & $4.3(2.0-9.4)$ & $<0.001$ & 0 & $11(4)$ & $1.0(0.9-1.0)$ & 0.2 \\
\hline 1 or more new partners & $12(23)$ & $26(11)$ & $2.3(1.1-5.0)$ & 0.03 & 0 & $14(5)$ & $1.0(0.9-1.0)$ & 0.1 \\
\hline \multicolumn{9}{|l|}{ Symptoms } \\
\hline Pruritus & $23(43)$ & $161(69)$ & $0.3(0.2-0.6)$ & $<0.001$ & $26(59)$ & $187(65)$ & $0.7(0.4-1.5)$ & 0.3 \\
\hline Sore vulva & $9(17)$ & $74(32)$ & $0.4(0.2-0.9)$ & 0.02 & $6(14)$ & $52(18)$ & $0.7(0.3-1.8)$ & 0.3 \\
\hline Dysuria & $15(29)$ & $57(25)$ & $1.2(0.6-2.5)$ & 0.3 & $15(34)$ & $48(17)$ & $2.5(1.3-5.1)$ & 0.009 \\
\hline Dyspareunia & $13(25)$ & $74(33)$ & $0.7(0.3-1.4)$ & 0.2 & $8(18)$ & $75(26)$ & $0.6(0.3-1.4)$ & 0.2 \\
\hline Abdominal pain & $28(53)$ & $112(48)$ & $1.2(0.7-2.2)$ & 0.3 & $20(46)$ & $107(37)$ & $1.4(0.7-2.7)$ & 0.2 \\
\hline Fever & $9(17)$ & $15(7)$ & $3.0(1.2-7.2)$ & 0.02 & $4(9)$ & $7(2)$ & $4.0(1.1-14.4)$ & 0.04 \\
\hline \multicolumn{9}{|l|}{ Signs } \\
\hline Scratch marks & $12(23)$ & $82(35)$ & $0.5(0.3-1.1)$ & 0.06 & $14(32)$ & $105(36)$ & $0.8(0.4-1.6)$ & 0.3 \\
\hline Vulvitis & $8(15)$ & $53(23)$ & $0.6(0.3-1.4)$ & 0.2 & $5(11)$ & $49(17)$ & $0.6(0.2-1.7)$ & 0.2 \\
\hline Malodorous discharge & $12(23)$ & $40(17)$ & $1.4(0.7-3.0)$ & 0.2 & $9(21)$ & $74(26)$ & $0.8(0.3-1.6)$ & 0.3 \\
\hline Moderate/copious discharge & $40(77)$ & $144(64)$ & $1.9(0.9-3.8)$ & 0.05 & $37(88)$ & $239(85)$ & $1.3(0.5-3.7)$ & 0.4 \\
\hline Yellow/bloody discharge & $28(55)$ & $66(29)$ & $3.0(1.6-5.5)$ & 0.001 & $14(33)$ & $96(34)$ & $1.0(0.5-1.9)$ & 0.6 \\
\hline Purulent or bloody endocervical mucopus & $23(43)$ & $55(24)$ & $2.5(1.3-4.6)$ & 0.004 & $18(41)$ & $87(30)$ & $1.6(0.8-3.1)$ & 0.1 \\
\hline Cervix erythema & $20(38)$ & $47(20)$ & $2.4(1.3-4.5)$ & 0.007 & $5(11)$ & $40(14)$ & $0.8(0.3-2.2)$ & 0.4 \\
\hline Cervix friability & $23(43)$ & $61(27)$ & $2.1(1.1-4.0)$ & 0.01 & $10(23)$ & $38(13)$ & $1.9(0.9-4.2)$ & 0.09 \\
\hline Painful adnexa & $19(36)$ & $56(24)$ & $1.8(0.9-3.4)$ & 0.06 & $9(21)$ & $38(13)$ & $1.7(0.8-3.8)$ & 0.1 \\
\hline Motion tenderness & $12(23)$ & $33(14)$ & $1.8(0.9-3.7)$ & 0.09 & $3(7)$ & $7(2)$ & $2.9(0.7-11.9)$ & 0.1 \\
\hline
\end{tabular}

^The denominators for the different categories are sometimes smaller than the totals owing to missing variables.

Table 4 Sensitivity, specificity, and positive predictive value (PPV) for gonococcal and chlamydial infections for different diagnostic algorithms for vaginal discharge, among 621 women, and comparing pregnant with non-pregnant women

\begin{tabular}{|c|c|c|c|c|c|c|c|c|c|}
\hline \multirow[b]{2}{*}{ Algorithm } & \multicolumn{3}{|c|}{ Total $(n=621)$} & \multicolumn{3}{|c|}{ Non-pregnant $(n=287)$} & \multicolumn{3}{|c|}{ Pregnant $(n=334)$} \\
\hline & $\begin{array}{l}\text { Sensitivity } \\
(\%)\end{array}$ & $\begin{array}{l}\text { Specificity } \\
(\%)\end{array}$ & $\begin{array}{l}P P V \\
(\%)\end{array}$ & $\begin{array}{l}\text { Sensitivity } \\
(\%)\end{array}$ & $\begin{array}{l}\text { Specificity } \\
(\%)\end{array}$ & $\begin{array}{l}P P V \\
(\%)\end{array}$ & $\begin{array}{l}\text { Sensitivity } \\
(\%)\end{array}$ & $\begin{array}{l}\text { Specificity } \\
(\%)\end{array}$ & $\begin{array}{l}P P V \\
(\%)\end{array}$ \\
\hline A & 42 & 63 & 18 & 47 & 57 & 20 & 36 & 69 & 15 \\
\hline B & 50 & 58 & 18 & 53 & 52 & 20 & 45 & 63 & 16 \\
\hline C & 59 & 61 & 22 & 66 & 54 & 24 & 50 & 67 & 18 \\
\hline D & 45 & 68 & 21 & 55 & 71 & 30 & 33 & 66 & 13 \\
\hline E & 42 & 73 & 22 & 43 & 76 & 29 & 41 & 70 & 17 \\
\hline $\mathrm{F}$ & 78 & 42 & 20 & 85 & 38 & 24 & 70 & 46 & 16 \\
\hline
\end{tabular}

All the above algorithms require the presence of vaginal discharge.

$\mathrm{A}=$ algorithm as in use in Kenya (complaint of abdominal pain and abdominal tenderness on examination).

$\mathrm{B}=$ modified Kenyan algorithm (complaint of abdominal discharge and no examination performed).

$\mathrm{C}=\mathrm{WHO}$ algorithm (risk score except for symptoms in partner)

$\mathrm{D}=$ yellow or bloody discharge visible on examination of vagina.

$\mathrm{E}=$ endocervical mucopus on speculum examination.

$\mathrm{F}=$ risk score positive and/or yellow or bloody vaginal discharge visible.

EVALUATION OF ALGORITHMS

The results of the validation of the different algorithms for pregnant and non-pregnant women are presented in table 4. Applying the Kenyan national policy algorithm resulted in a sensitivity of $42 \%$ and a specificity of $63 \%$ for gonococcal or chlamydial cervicitis, with a PPV of $18 \%$ (algorithm A). The Kenyan algorithm but without an abdominal examination, hence relying on the complaint of abdominal pain alone (B), resulted in a higher sensitivity and somewhat lower specificity. The algorithm with risk score $\mathrm{C}$ gave a sensitivity of $59 \%$ and a specificity of $61 \%$ with a PPV of $22 \%$. Algorithm D relies on the inspection of the colour of the vaginal discharge and does not necessarily require a speculum examination. Algorithm E requires inspection of the cervix by speculum examination. Both algorithms D and $\mathrm{E}$ result in a sensitivity and a specificity similar to algorithm A but with marginal higher PPV. Algorithm F, a combination of risk score and presence of yellow or bloody vaginal discharge, resulted in the highest sensitivity but had low specificity. Among non-pregnant women, all algorithms produced a higher sensitivity. Among pregnant women, however, the different algorithms had a lower sensitivity.

The overall correct treatment rate of the different flow charts varied and was in general higher among non-pregnant women, except for flow charts D and E. The cost per case varied from $\$$ USO.5 to $\$ 0.9$. The cost per true cervical infection treated varied from $\$ 6.7$ for the risk score algorithm to $\$ 8.3$ for the Kenyan algorithm. Algorithm F identified more true cervical infections than the other flow charts but the overall cost was substantially higher (table not presented here).

\section{Discussion}

The most common pathogens found among women complaining of vaginal discharge in this study were Candida albicans and Trichomonas vaginalis. This is not surprising and has been shown in similar studies among women presenting with vaginal discharge in other African settings. ${ }^{10-12}$ The prevalence of bacterial vaginosis in our study was low compared with other studies in the region ${ }^{13} 14$ and is probably an underestimation. Indeed, we used the clinical 
diagnosis for bacterial vaginosis, which is subject to interpretation by the clinician. Furthermore, the identification of clue cells depends on the level of training of the person performing the microscopic examination. Also, the quality of the Gram stain might have influenced the results. The combination of these factors might have resulted in an underestimated prevalence.

Overall, no cervical or vaginal pathogen or condition was found in $28 \%$ of the women. Again, this is similar to the findings in Mwanza where $23 \%$ of the women at the STD clinic and $27 \%$ at the antenatal clinic had no demonstrable pathogen. ${ }^{12}$ We found a prevalence of cervical infections of $16 \%$. Non-pregnant women had significantly more gonococcal infection, genital ulcers, and HIV infection but pregnant women had more candidiasis. The high proportion of pregnant women with an STD is a cause for concern. Gonococcal and chlamydial infections, as well as syphilis and HIV, are associated with adverse obstetric outcome. ${ }^{15-19}$ The results of this study show that there is an urgent need for public health measures to improve STD control during pregnancy.

The prevalence of the different RTI varied between the different clinics under study. Surprisingly, the prevalence rates for most RTI were higher in one of the PHC clinics than in the STD referral clinic. Although the two PHC clinics where enrolment took place are located very close to each other, the prevalences varied here also, indicating that the populations attending the different clinics are quite different. Lower socioeconomic conditions seem to be the basis for higher STI prevalences. Health staff at all levels of medical facilities should become aware that all women are to be considered at high risk, and that their treatment inclusive of health education and counselling has to be stressed. The stereotype image that only patients attending the STD clinic are at high risk has to be revised urgently so as to eliminate the stigma still attached to STDs and hence to make STD control more effective.

In this study of symptomatic women, the association of the classic clinical symptoms and signs with the presence of gonococcal and/or chlamydial infection was quite different among pregnant and non-pregnant women. Several demographic risk determinants and signs were predictive of cervical infection among nonpregnant women while hardly any were among pregnant women. As a result, the various flow charts that were tested performed systematically better in the group of non-pregnant women. The algorithm in use in Kenya as national policy had a sensitivity of $42 \%$ and a specificity of $63 \%$ for the detection of $N$ gonorrhoeae or $C$ trachomatis and thus failed to discriminate between infected and uninfected women. This algorithm relies on bimanual examination of the patients, and hence requires an examination table and gloves, items often not available in the health centres. As a result, the algorithm is, in practice, often applied without performing this examination. Furthermore, the bimanual examination is subject to interpretation and depends on the experience of the person performing it. In our study the physical examinations were done by medical doctors, and they reported almost all women in the study to have abdominal tenderness. In practice in the health centres, the examinations are performed by nurses who are less well trained; hence we can assume that the results would be worse. We therefore also tested the Kenyan algorithm but without performing the bimanual examination (algorithm B). The results are similar and in fact have a higher sensitivity.

The risk score used to discriminate cervical infection, as promoted by the WHO, has been evaluated in several African settings. ${ }^{12}{ }^{14}{ }^{20-23} \mathrm{We}$ used a simplified risk score without symptoms in the partner as this information is sensitive and difficult to obtain. Personal communication with healthcare workers and data from our other studies (unpublished) suggested that symptoms in the male partner are seldom known by the woman and are hence unreliable. This was confirmed in a study by Thomas et $a l^{14}$ who found that only $2 \%$ of mostly married women reported partners having symptoms. Hence, including this risk factor would only increase the specificity but not the sensitivity of the flow chart. The algorithm we tested (C) was based on presence of any of the risks: being single, being less than 20 years old, having had multiple or a new partner in the past 3 months. An earlier study in Nairobi also reported being single and having multiple sex partners to be associated with gonococcal infection in pregnant women. ${ }^{24}$ We considered that for a risk score to be applicable it has to be simple to use. The healthcare worker in a busy health centre has no time and patience to apply scoring systems with weighted risks or calculations of scores. In our study a risk score based on presence of at least two of the risks would have resulted in a sensitivity of only $30 \%$. Our risk score algorithm (C) resulted in a sensitivity of $66 \%$ with PPV of $24 \%$ among non-pregnant women. The results among pregnant women were less good and comparable with what Mayaud et al had found in Mwanza. ${ }^{12}$ Using this flow chart, the rate of overtreatment in non-pregnant women was $46 \%$ while it was $33 \%$ in pregnant women.

We included several signs in the flow chart. Among pregnant women, however, none of these signs was associated with cervical infection. This is contrary to findings from Thomas et al who found that among asymptomatic women in Nairobi, cervical friability was associated with cervical infection. ${ }^{14}$ An earlier study in Nairobi among pregnant women had identified friability and endocervical mucopus as predictors of cervical infection. ${ }^{25}$ And in another study in Nairobi, Temmerman et al reported an association between gonococcal infection post partum and cervical mucopus. ${ }^{26}$ We tested algorithm D based on observation of the colour of vaginal discharge. This algorithm does not require the use of a speculum. Algorithm E was based on observation of the cervix hence requiring speculum examination that is seldom possible in health centres in Kenya. Both resulted in too low sensitivity to 
be of value. Algorithm F combined the risk assessment and the inspection of the vaginal discharge. In both groups of women high sensitivity was reached but with low specificity. Several other combinations of risks, symptoms, and signs were tested but all performed worse.

While none of the tested algorithms reached acceptable levels of sensitivity and specificity, the algorithm with risk score performed somewhat better than the algorithm actually in use in Kenya and would identify more true cervical infections although at a higher overall cost. Introducing the risk assessment among nonpregnant women could be an option. It is, however, doubtful that the introduction of the risk score into the existing algorithm, which would imply printing of new charts and retraining of health staff, is worthwhile. Among pregnant women this flow chart would fail to identify cervical infections. Treatment of pregnant women with vaginal discharge might be considered for both vaginal and cervical infections on the first visit. Further operational research is needed to assess the rate of follow up and return visits among these women. We can conclude that simple, cheap, and reliable tests for the diagnosis of cervical infection in women are still urgently needed.

The authors thank the staff of the Nairobi City Council facilities where this study took place, whose collaboration was much appreciated. They are indebted to Dr Joel Rakwar for critical review of the article and to Laurence De Baets for secretarial services.

The study was supported by a grant from the European Union (DG VIII-7 RPR 28-1994).

Contributors: KF designed the study, supervised the implementation, data analysis, interpretation, and writing the paper; $\mathrm{NK}, \mathrm{WJ}$, and $\mathrm{BE}$ were responsible for actual fieldwork, data analysis, and interpretation, and review of draft of paper; PC interpreted the results, reviewed the draft; JN-A was responsible for design of the study, facilitation of implementation of fieldwork, review of draft; PK facilitated actual fieldwork and reviewed the draft; JB was responsible for the laboratory aspect of the study, and review of draft; MT designed the study, interpreted the results, reviewed drafts, and had overall responsibility for the study.

1 Kreiss J, Willeford D, Hensel M, et al. Association between cervical inflammation and cervical shedding of human immunodeficiency virus DNA. F Infect Dis 1994;170:1597601

2 Laga M, Nzila N, Goeman J. The interrelationship of sexually transmitted diseases and HIV infection: implications
for the control of both epidemics in Africa. AIDS 1991;5(suppl):S55-63.

3 Plummer F, Simonsen J, Cameron D, et al. Co-factors in male-female sexual transmission of human immunodeficiency virus type 1. F Infect Dis 1991;163:233-9.

4 Laga M, Alary M, Nzila Z, et al. Condom promotion, sexually transmitted diseases treatment and declining incidence of HIV-1 infection in female Zairian sex workers. Lancet 1994;344:246-8.

5 Grosskurth H, Mosha F, Todd J, et al. Impact of improved treatment of sexually transmitted diseases in rural Tanzania: results of a randomised controlled trial. Lancet 1995;346:530-6.
6 Mayaud P, Mosha F, Todd J, et al. Improved treatment services significantly reduce the prevalence of sexually trans-
mitted diseases in rural Tanzania: results of a randomized mitted diseases in rural Tanzania: results
controlled trial. AIDS 1997;11:1873-80.

$7 \mathrm{WHO} / \mathrm{GPA}$. Informal technical working group meeting on STD activities in GPA. The evaluation of algorithms for the diagnosis and treatment of vaginal discharge. Agenda item No IV, background paper No 5. Geneva: WHO, 1993.

8 Hillier S, Holmes KK. Bacterial vaginosis. In: Adimora AA, Hamilton H, Holmes KK, Sparling PF, eds. Sexually transmitted diseases. 2nd ed. New York: McGraw-Hill, 1990:54759 .

9 Easmon C, Hay P, Ison C. Bacterial vaginosis: a diagnostic approach. Genitourin Med 1992;68:134-8.

10 Costello Daly C, Wangel AM, Hoffman IF, et al. Validation of the WHO diagnostic algorithm and development of an alternative scoring system for the management of women presenting with vaginal discharge in Malawi. Sex Transm Inf 1998;4(Suppl 1):S50-8.

11 Alary M, Baganizi E, Guedeme A, et al. Evaluation of clinical algorithms for the diagnosis of gonococcal and chlamydial infections among men with urethral discharge or dysuria and women with vaginal discharge in Benin. Sex Transm Inf 1998;74(Suppl 1):S44-9.

12 Mayaud P, Ka-Gina G, Cornelissen J, et al. Validation of a WHO algorithm with risk assessment for the clinical management of vaginal discharge in Mwanza, Tanzania. Sex Transm Inf 1998;74(Suppl 1):S77-84.

13 Wawer M, Gray R, Sewankambo N, et al. A randomized, community trial of intensive sexually transmitted disease control for AIDS prevention, Rakai, Uganda. AIDS 1998;12:1211-25.

14 Thomas T, Choudri S, Kariuki C, et al. Identifying cervical infection among pregnant women in Nairobi, Kenya: limitations of risk assessment and symptom based approaches. Genitourin Med 1996;2:334-8.

15 Ryder R, Temmerman M. The effect of HIV-1 infection during pregnancy and the perinatal period on maternal and child health in Africa. AIDS 1991;5(Suppl):S75-85.

16 Temmerman M, Lopita M, Sanghvi H, et al. The role of maternal syphilis, gonorrhoea and HIV-1 infections in spontaneous abortion. Int $\mathcal{F}$ STD AIDS 1992;3:418-22.

17 Temmerman M, Chomba E, Ndinya-Achola J, et al. Maternal human immunodeficiency virus- 1 infection and pregnancy outcome. Obstet Gynecol 1994;83:495-501.

18 Leroy V, Ladner J, Nyiraziraje M, et al. Effect of HIV-1 on pregnancy outcome in women in Kigali, Rwanda, 19921994. AIDS 1998;12:643-50.

19 Temmerman M, Plummer F, Mirza N, et al. Infection with HIV as a risk factor for adverse obstetrical outcome. AIDS 1990;4:1087-93.

20 Vuylsteke B, Laga M, Alary M, et al. Clinical algorithms for the screening of women for gonococcal and chlamydial infection: evaluation of pregnant women and prostitutes in Zaire. Clin Infect Dis 1993;17:82-8.

21 Diallo MO, Ghys PD, Vuylsteke B, et al. Evaluation of simple diagnostic algorithms for Neisseria gonorrhoeae and Chlamydia trachomatis cervical infections in female sex workers in Abidjan, Côte d'Ivoire. Sex Transm Inf 1998;74(Suppl 1):S106-11.

22 Mayaud P, Grosskurth H, Changalucha J, et al. Risk assessment and other screening options for gonorrhoea and chlamydial infections in women attending rural Tanzanian antenatal clinics. Bull World Health Organ 1995;73:621-30.

23 Germain M, Alary M, Guedeme A, et al. Evaluation of a screening algorithm for the diagnosis of genital infections with Neisseria gonorrhoeae and Chlamydia trachomatis among female sex workers in Benin. Sex Transm Dis 1997; 24:109-15.

24 Costello Daly C, Maggwa N, Mati J, et al. Risk factors for gonorrhoea, syphilis, and trichomonas infections among women attending family planning clinics in Nairobi, Kenya. Genitourin Med 1994;70:155-61.

25 Braddick M, Ndinya-Achola J, Mirza N, et al. Towards developing a diagnostic algorithm for Chlamydia trachomatis and Neisseria gonorrhoeae cervicitis in pregnancy. Genitourin Med 1990;66:62-5.

26 Temmerman M, Plummer F, Farah A, et al. Gonorrhoea in pregnancy. F Obstet Gynecol 1992;12:162-6. 